\title{
Computational Method for Bearing Capacity of Steel tube Reinforced Concrete Short Column under Axial Loading
}

\author{
LIU Jin Sheng ${ }^{1, a}$, XIE Rui Li ${ }^{2, b}$ and QIAN Yong Jiu ${ }^{3, c}$ \\ ${ }^{1}$ School of Civil Engineering, Southwest Jiaotong University, Chengdu, Sichuan 610031, PR China \\ ${ }^{2}$ School of Mechanics and Engineering, Southwest Jiaotong University, Chengdu, Sichuan 610031, \\ PR China \\ a29232446@qq.com, ${ }^{b} 973436645 @ q q . c o m,{ }^{c}$ yjqian@home.swjtu.edu.cn
}

Keywords: Constitutive Relationship, Reinforced Concrete, Piers Reinforcement, Steel Pipe Reinforcement

\begin{abstract}
The existing concrete column reinforced by steel tube is commonly used in engineering. However, the computational theory of bearing capacity of the structure after reinforcement is insufficient at present. In the case of the initial stress of existing concrete column is relatively lower, the computational formula of axial bearing capacity for short column pier reinforced by steel tube has been deduced from the modified stress-strain curve of concrete filled steel tube. Comparing the computational results with the correspondent experimental data shows that the formula can provide support for the computation analysis of bearing capacity of reinforcement pier in engineering practice.
\end{abstract}

\section{Introduction}

Currently the bearing capacity and basic mechanics property and experiments of steel tube reinforced concrete have already been relatively mature. Based on plenty of experimental data on bearing capacity of steel tube reinforced concrete, the constitutive relationship curve of steel tube reinforced concrete has been proposed by $\mathrm{Han}^{[1]}$. Zhong ${ }^{[2]}$ proposed the unified theory of steel tube reinforced concrete. Moreover, the limit bearing capacity of concrete reinforced steel tube is studied by the limit equilibrium method, as done by $\mathrm{Cai}^{[3]}$. All of them provide a good theoretical basis for the bearing capacity analysis of steel tube reinforced concrete. Because former concrete column in the reinforced structure is subjected to secondary load, the analysis of the secondary stress is different from ordinary concrete-filled steel tube. Therefore, this work mainly focuses on the theoretical analysis and computation of bearing capacity of steel tube reinforced concrete short column.

\section{Structural Analysis of Secondary Stress and Improved Concrete's Stress-Strain Curve}

The basic assumptions. After the reinforcement of the core column, the core column and filled concrete work together, the section of the composite structure formed after core column was reinforced can be assumed as a flat cross section. Effects of concrete shrinkage and temperature are not taken into account. Stress-strain relationship of reinforcement rebar in the core column is perfect elastic-plastic model. The stress-strain curve of ordinary reinforced concrete column before core column's reinforcement can be calculated by Hognestad model as:

$$
\sigma_{c}=\left\{\begin{array}{l}
\sigma_{0}\left[\frac{2 \varepsilon_{c}}{\varepsilon_{0}}-\left(\frac{\varepsilon_{c}}{\varepsilon_{0}}\right)^{2}\right] \quad \varepsilon_{c} \leq \varepsilon_{0} \\
\sigma_{0}\left[1-0.15\left(\frac{\varepsilon_{c}-\varepsilon_{0}}{\varepsilon_{c u}-\varepsilon_{0}}\right)\right] \varepsilon_{0}<\varepsilon_{c} \leq \varepsilon_{c u}
\end{array}\right.
$$

The concrete filled by steel tube model is proposed by Han ${ }^{[1]}$ and shown as below: 


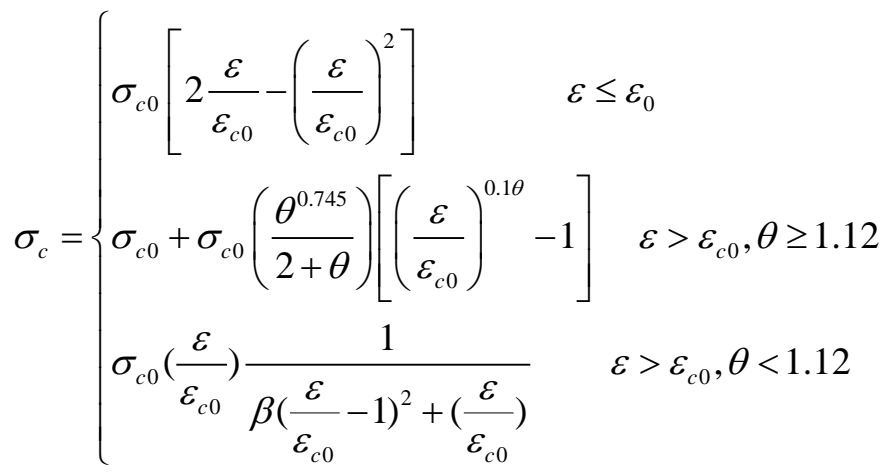

The stress state after reinforcement and improved stress-strain curve of concrete.

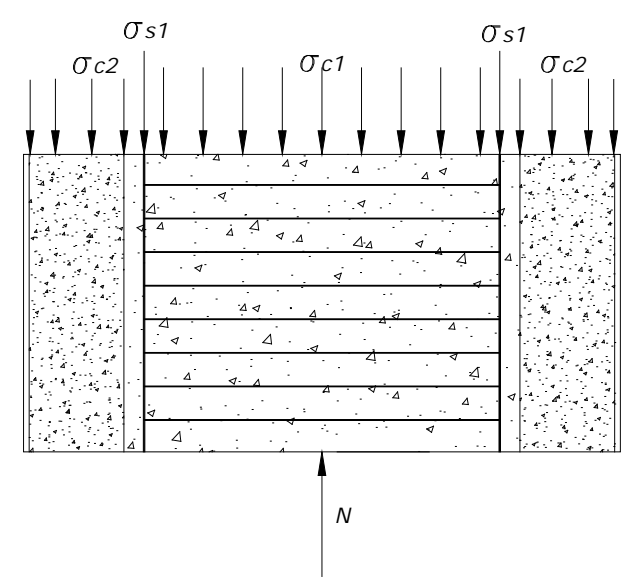

Fig. 1 Diagram of bearing capacity of reinforced column

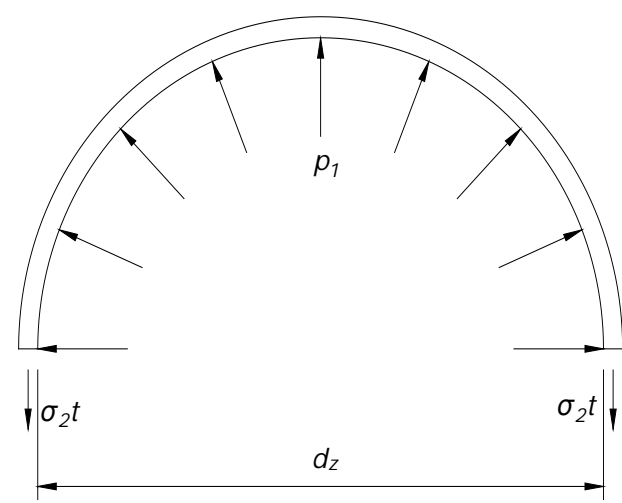

Fig. 3 Schematic of the radial pressure of steel tube by concrete-filled

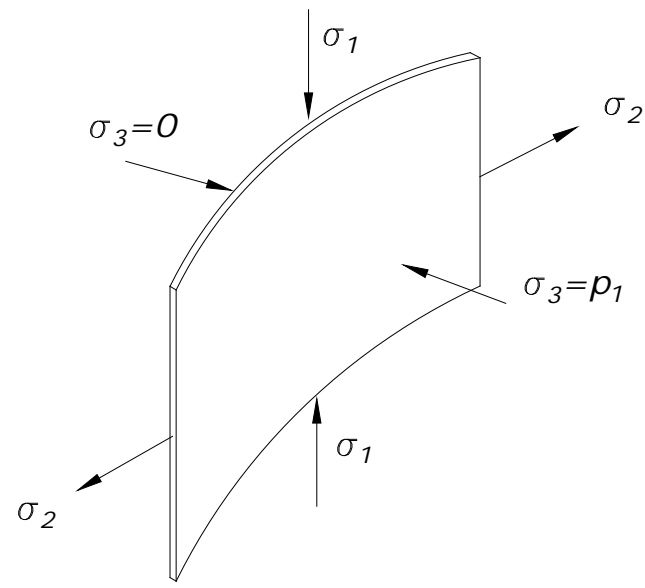

Fig. 2 Diagram of steel tube infinitesimal body

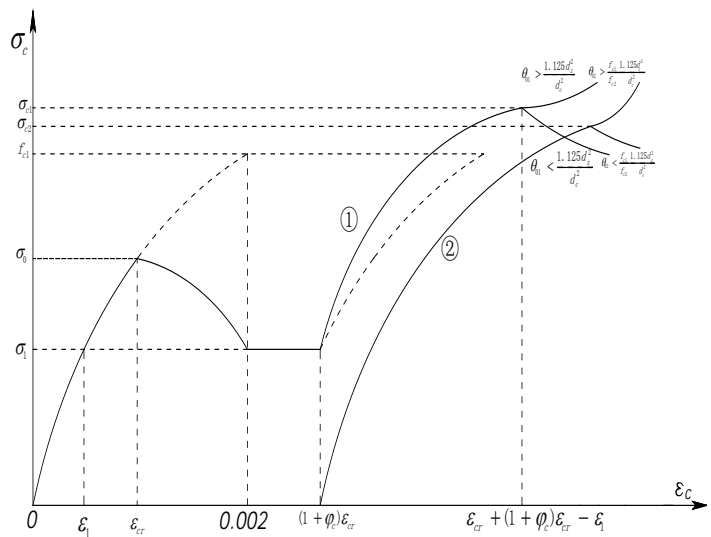

Fig. 4 Constitutive relationship of core and filled concrete affected by creep

The relationship between the radial pressure that steel tube received from concrete-filled and the hoop tensile stress of steel tube can be obtained from Fig. 2 and Fig. 3 as $\sigma_{2} t=\frac{d_{z}}{2} p_{1}$. Core column and filled concrete are in the triaxial compression situation after reinforcement and the thin-walled steel yields: $p=p_{1}=\frac{2 t}{d_{z}} \cdot f_{s}$. Because concrete inside the steel tube is constituted by core concrete and filled concrete, here, $\theta_{1}=\frac{A_{s} f_{s}}{A_{c 1} f_{c 1}}$ is defined. $\theta_{1}$ is a reinforcement indicator that former concrete column received from reinforced steel tube. According to the linear equation of yield condition of 
triaxial compression core concrete $\sigma_{c}=f_{c}+k p$ and the nonlinear equation $\sigma_{c}=f_{c}\left(1+1.5 \sqrt{\frac{p}{f_{c}}}+2 \frac{p}{f_{c}}\right)$, the bearing capacity of former column that:

$$
N_{c 1}=A_{c 1} f_{c 1}\left(1+\frac{k}{2} \cdot\left(\frac{d_{c}}{d_{z}}\right)^{2} \theta_{1}\right)=A_{c 1} f_{c 1}\left(1+1.5 \sqrt{\frac{1}{2}\left(\frac{d_{c}}{d_{z}}\right)^{2} \theta_{1}}+\left(\frac{d_{c}}{d_{z}}\right)^{2} \theta_{1}\right)
$$

when $k=4$, then critical cut-off value $\left[\theta_{1}\right]=\frac{1.125 d_{z}^{2}}{d_{c}^{2}}$. Similarly, $\left[\theta_{2}\right]=\frac{f_{c 1}}{f_{c 2}} \frac{1.125 d_{z}^{2}}{d_{c}^{2}}$.

Where, $A_{c 1}, A_{c 2}, A_{s}, A_{s 1}$ are the cross-sectional areas of core concrete, filled-concrete, steel and longitudinal rebar, respectively; $\sigma_{c 1}, \sigma_{c 2}, \sigma_{1}, \sigma_{s 1}$ are the longitudinal stresses of core concrete, filled-concrete, steel and longitudinal rebar, respectively; $f_{s}$ is the yield limit of steel tube, $d_{c}$ and $d_{z}$ are the diameters of core concrete column and concrete after reinforcement, respectively; $\varepsilon_{c 01}$ and $\varepsilon_{c 02}$ are the peak strains of the reinforced core concrete and concrete-filled, respectively; $N_{1}$ is the initial force of core column. $\varepsilon_{1}$ and $\sigma_{1}$ are the initial strain and stress of core column. In Fig. 4, (1) and (2) are stress-strain curves of core and filled concrete affected by creep, respectively; $\varphi_{c}$ is creep coefficient, $\varepsilon_{c r}$ is instantaneous strain of core column under constant load. $\theta_{1}$ and $\theta_{2}$ are reinforcement indicators that former concrete column and filled concrete reinforced by steel tube.

The stress of core pillar's concrete after reinforcement has changed from one-way axial compressed station before reinforcement to triaxial compression situation under the constraints of steel tube and filled concrete. Therefore, the theory that concrete strength increases under triaxial compression is adopt here, the compressive strength of core concrete column after reinforcement is $\sigma_{c}=\sigma_{0}+k p$.The stress-strain cure of core concrete column before reinforcement can be calculated by Hognestad's equation and results are shown in Fig.4. When the core concrete is reinforced, filled concrete and steel tube are unconstrained, it yields $p=0$. However, when the peak strain of core concrete column is $\varepsilon_{c 01}, p_{\max }=\frac{2 f_{s} t}{d_{z}}$, the strain range of $k p$ can be written as: $\left[\left(1+\phi_{c}\right) \varepsilon_{c r}, \varepsilon_{c 01}+\left(1+\phi_{c}\right) \varepsilon_{c r}-\varepsilon_{1}\right]$, and thus its value in the strain range based on linear interpolation is $\left[0, k p_{\max }\left(2 \frac{\varepsilon-\left(1+\phi_{c}\right) \varepsilon_{c r}}{\varepsilon_{c 01}-\varepsilon_{1}}-\left(\frac{\varepsilon-\left(1+\phi_{c}\right) \varepsilon_{c r}}{\varepsilon_{c 01}-\varepsilon_{1}}\right)^{2}\right)\right]$, the peak strain is thought to be equal to steel tube-concrete's strain by $\operatorname{Han}^{[1]}$ since the initial stress level of core concrete column is lower under secondary load. At the same time, according to the continuity of core concrete's stress and strain before and after reinforcement, and stress and strain of filled-concrete follow behind core concrete's ones under secondary load, Integrate Hognestad's equation, constitutive model of concrete filled steel tube and yield conditions of core concrete under triaxial compression, the stress-strain relationships of reinforced core column's concrete and filled-concrete are shown in Table 1.

Table 1 Improved Han’s equation for constitutive relationship of concrete

Constitutive modelfor core concrete

when $\left(1+\phi_{c}\right) \varepsilon_{c r} \leq \varepsilon \leq \varepsilon_{c o 1}+\left(1+\phi_{c}\right) \varepsilon_{c r}-\varepsilon_{1}$

$\sigma_{c 1}=\left(\sigma_{c 01}-\sigma_{1}\right)\left[2 \frac{\varepsilon}{\varepsilon_{c 01}-\varepsilon_{1}} \frac{\varepsilon_{c 01}+\left(1+\phi_{c}\right) \varepsilon_{c r}-\varepsilon_{1}}{\varepsilon_{c 01}-\varepsilon_{1}}-\left(\frac{\varepsilon}{\varepsilon_{c 01}-\varepsilon_{1}}\right)^{2}\right]+k_{2}+k p_{\max }\left[2 \frac{\varepsilon-\left(1+\phi_{c}\right) \varepsilon_{c r}}{\varepsilon_{c 01}-\varepsilon_{1}}-\left(\frac{\varepsilon-\left(1+\phi_{c}\right) \varepsilon_{c r}}{\varepsilon_{c 01}-\varepsilon_{1}}\right)^{2}\right]$

when $\varepsilon \geq \varepsilon_{c 01}+\left(1+\phi_{c}\right) \varepsilon_{c r}-\varepsilon_{1}$ 


$$
\sigma_{c 1}=\left\{\begin{array}{l}
\sigma_{c 01}+\sigma_{c 01}\left(\frac{\theta_{01}{ }^{0.745}}{2+\theta_{1}}\right)\left[\left(\frac{\varepsilon-\left(1+\phi_{c}\right) \varepsilon_{c r}+\varepsilon_{1}}{\varepsilon_{c 01}}\right)^{0.1 \theta_{01}}-1\right]+k p_{\max }, \quad \theta_{01} \geq \frac{1.125 d_{z}^{2}}{d_{c}^{2}} \\
\sigma_{c 01}\left(\frac{\varepsilon-\left(1+\phi_{c}\right) \varepsilon_{c r}+\varepsilon_{1}}{\varepsilon_{c 01}}\right) \frac{1}{\beta\left(\frac{\varepsilon-\left(1+\phi_{c}\right) \varepsilon_{c r}+\varepsilon_{1}}{\varepsilon_{c 01}}-1\right)^{2}+\frac{\varepsilon-\left(1+\phi_{c}\right) \varepsilon_{c r}+\varepsilon_{1}}{\varepsilon_{c 01}}}+k p_{\max }, \theta_{01}<\frac{1.125 d_{z}^{2}}{d_{c}^{2}}
\end{array}\right.
$$

Constitutive model for filled concrete

When $\left(1+\phi_{c}\right) \varepsilon_{c r} \leq \varepsilon \leq \varepsilon_{c o 2}+\left(1+\phi_{c}\right) \varepsilon_{c r}$

$$
\sigma_{c 2}=\sigma_{c 02}\left[2 \frac{\varepsilon-\left(1+\phi_{c}\right) \varepsilon_{c r}}{\varepsilon_{c 02}}-\left(\frac{\varepsilon-\left(1+\phi_{c}\right) \varepsilon_{c r}}{\varepsilon_{c 02}}\right)^{2}\right]
$$

When $\varepsilon \geq \varepsilon_{c 02}+\left(1+\phi_{c}\right) \varepsilon_{c r}$

$$
\begin{aligned}
& \sigma_{c 2}=\left\{\begin{array}{l}
\sigma_{c 02}+\sigma_{c 02}\left(\frac{\theta_{02}^{0.745}}{2+\theta_{02}}\right)\left[\left(\frac{\varepsilon-\left(1+\phi_{c}\right) \varepsilon_{c r}}{\varepsilon_{c 02}}\right)^{0.1 \theta_{02}}-1\right], \theta_{02} \geq \frac{1.125 d_{z}^{2}}{d_{c}^{2}} \\
\sigma_{c 02}\left(\frac{\varepsilon-\left(1+\phi_{c}\right) \varepsilon_{c r}}{\varepsilon_{c 02}}\right) \frac{1}{\beta\left(\frac{\varepsilon-\left(1+\phi_{c}\right) \varepsilon_{c r}}{\varepsilon_{c 02}}-1\right)^{2}+\frac{\varepsilon-\left(1+\phi_{c}\right) \varepsilon_{c r}}{\varepsilon_{c 02}}, \theta_{02}<\frac{1.125 d_{z}^{2}}{d_{c}^{2}}} \\
k_{2}=\sigma_{1}-\left(\sigma_{c 01}-\sigma_{1}\right)\left[\frac{2\left(1+\phi_{c}\right) \varepsilon_{c r}}{\varepsilon_{c 01}-\varepsilon_{1}}+\left(\frac{\left(1+\phi_{c}\right) \varepsilon_{c r}}{\varepsilon_{c 01}-\varepsilon_{1}}\right)^{2}\right] \\
\sigma_{c 02}=f_{c 2}\left(1+\frac{k}{2} \cdot \frac{f_{c 1}}{f_{c 2}}\left(\frac{d_{c}}{d_{z}}\right)^{2} \theta_{1}\right), \sigma_{c 01}=f_{c 1}, \theta_{01}=\frac{A_{s} f_{s}}{\left(A_{c 1}+A_{c 2}\right) f_{c k 1}}, \theta_{02}=\frac{f_{c 1}}{f_{c 2}} \theta_{01}
\end{array}\right.
\end{aligned}
$$

The influence coefficient of initial stress on bearing capacity under secondary load. According to references ${ }^{[4-6]}$, when the initial stress level of former's column is not high $\left(\beta^{\prime}<0.5\right)$, axial compressive limit bearing capacity of reinforced structure cannot almost be affected. In this work, the influence coefficient of initial stress on bearing capacity of reinforced structure can be fitted with quadratic, thus the influence coefficient of initial stress can be calculated as:

$$
\gamma_{c}=2\left(1-0.5 \beta^{\prime}\right)-\left(1-0.5 \beta^{\prime}\right)^{2}=1-\left(0.5 \beta^{\prime}\right)^{2}
$$

Solution of the limit bearing capacity under secondary load. When the reinforced structural column under secondary load subjected to a limit load, the longitudinal rebar yields in the limit situation due to a low initial stress. The longitudinal stress of steel tube is too small to calculate. According to mechanical characteristics of core concrete and filled concrete and improved constitutive relationship of concrete, when the stress-strain curve of core concrete column is I and $\theta_{01}>\frac{1.125 d_{z}^{2}}{d_{c}^{2}}$, the static equilibrium can be established according to Fig. 1 as

$$
\begin{aligned}
& N=\gamma_{c}\left(A_{c 1} \sigma_{c 1}+A_{c 2} \sigma_{c 2}\right)+A_{s 1} f_{y 1}=\gamma_{c} A_{c 1} f_{c 1}\left[1+\left(\frac{\theta_{01}^{0.745}}{2+\theta_{01}}\right)\left[\left(\frac{\varepsilon-\left(1+\phi_{c}\right) \varepsilon_{c r}+\varepsilon_{1}}{\varepsilon_{c 01}}\right)^{0.1 \theta_{01}}-1\right]\right] \\
& +\gamma_{c} A_{c 1} k p_{M A X}+\gamma_{c} A_{c 2} f_{c 2}\left(1+\frac{k}{2} \cdot \frac{f_{c 1}}{f_{c 2}}\left(\frac{d_{c}}{d_{z}}\right)^{2} \theta_{1}\right)\left[2 \frac{\varepsilon-\left(1+\phi_{c}\right) \varepsilon_{c r}}{\varepsilon_{c 02}}-\left(\frac{\varepsilon-\left(1+\phi_{c}\right) \varepsilon_{c r}}{\varepsilon_{c 02}}\right)^{2}\right]+A_{s 1} f_{y 1}
\end{aligned}
$$

Then, 


$$
\begin{aligned}
& \frac{d N}{d \varepsilon}=\gamma_{c} A_{c 1} f_{c 1}\left(\frac{\theta_{01}^{0.745}}{2+\theta_{01}}\right) \frac{0.1 \theta_{01}\left[\varepsilon-\left(1+\phi_{c}\right) \varepsilon_{c r}+\varepsilon_{1}\right]^{0.1 \theta_{01}-1}}{\varepsilon_{c 01}}+ \\
& \gamma_{c} A_{c 2} f_{c 2}\left(1+\frac{k}{2} \cdot \frac{f_{c 1}}{f_{c 2}}\left(\frac{d_{c}}{d_{z}}\right)^{2} \theta_{1}\right)\left[\frac{2}{\varepsilon_{c 02}}-\frac{2\left(\varepsilon-\left(1+\phi_{c}\right) \varepsilon_{c r}\right)}{\varepsilon_{c 02}^{2}}\right]=0
\end{aligned}
$$

The value of $\varepsilon^{\prime}$ corresponding to the maximum value can be obtained according to Eq. (6), substituting $\varepsilon^{\prime}$ into the static equilibrium Eq. (5), then the value of $N_{\max }$ can be obtained, which is the limit bearing capacity of steel tube reinforced structure affected by initial stress.In the same way, when $\theta_{01}<\frac{1.125 d_{z}^{2}}{d_{c}^{2}}$, the value of $N_{\max }$ can be obtained.

\section{The experimental verification}

In order to verify constitutive model of concrete proposed here, take into account a specimen of steel tube reinforced concrete short column subjected to initial load, the initial load is applied by post-tensioned method. After the original pier is applied by initial load, pouring, molding and conservation, the concrete is reinforced by steel welded ferrule. The original pier's surface is cut before strengthening, fine stone concrete is poured between steel tube and original pier, specific sizes are shown in Table 2.

Table 2 Sizes of specimen (mm)

\begin{tabular}{crrrrrrr}
\hline $\begin{array}{c}\text { specimen } \\
\text { number }\end{array}$ & size of original column & & $\begin{array}{c}\text { Thickness } \\
\text { of steel } \\
\text { tubes }\end{array}$ & $\begin{array}{c}\text { Thickness } \\
\text { of filled } \\
\text { concrete }\end{array}$ & $\begin{array}{c}\text { Diameter of } \\
\text { longitudinal }\end{array}$ & $\begin{array}{c}\text { Diameter } \\
\text { and } \\
\text { spacing of } \\
\text { stirrup }\end{array}$ \\
\hline S-01 & 250 & 1000 & 0.11 & 4 & 25 & $6 \varphi 12$ & $6 \varphi 150$ \\
\hline
\end{tabular}

The standard strength of original column and filled concrete are respectively 36.3MPa and 38.1 MPa, material properties of steel tube and rebar are shown in table 3.

Table 3 Material properties of steel tube and rebar

\begin{tabular}{ccccc}
\hline Materials & $\begin{array}{c}\text { thickness of steel } \\
\text { tube/ diameter of } \\
\text { rebar }(\mathrm{mm})\end{array}$ & $\begin{array}{c}\text { ultimate strength } \\
f_{u k}(\mathrm{MPa})\end{array}$ & $\begin{array}{c}\text { yield strength } \\
f_{y k}(\mathrm{MPa})\end{array}$ & $\begin{array}{c}\text { tensile strength } \\
\text { of weld } \\
f_{t k}(\mathrm{MPa})\end{array}$ \\
\hline steel tube & 4 & 339 & 276 & 304 \\
rebar & 6.0 & 436 & 336 & - \\
& 12.0 & 476 & 350 & - \\
\hline
\end{tabular}

The measured values of limit bearing capacity of reinforced pier under secondary load obtained from tests are shown in table 4 .

Table 4 The test and calculational values for bearing capacity of structure with initial stress

\begin{tabular}{ccccc}
\hline Specimen number & $\begin{array}{r}\text { Stress level } \\
\text { indicator } \beta^{\prime}\end{array}$ & $N_{t}(\mathrm{KN})$ & $N_{p}$ & $N_{p} / N_{t}$ \\
\hline S-01 & 0.11 & 4396 & 4237 & 0.96 \\
\hline
\end{tabular}


$N_{t}$ in Table 4 is bearing capacity measured by test. $N_{p}$ is the ultimate axial compressed bearing capacity of reinforced structure calculated by the proposed method. The data in table 4 shows that the computation result by the proposed formula agrees with experiment well.

\section{Conclusions}

In case of core concrete reinforced structure reinforced by steel tube under secondary load, the forces are analyzed and the computation method for bearing capacity is derived based on the limit equilibrium method, also the constitutive model of concrete under secondary load is improved. A comparison between experimental and computational results shows that they are in a good agreement, which can provide a reference for the computation of bearing capacity of steel tube reinforced concrete structure in engineering.

\section{References}

[1] L.H. Han, Y.F. Yang: Modern steel tube-confined concrete structure technique (China Architecture \& Building Press, Beijing 2004).

[2] S.T. Zhong: Steel tube-confined concrete structure (Tsinghua University Press, Beijing 2003).

[3] S.H. Cai: Modern steel tube-confined concrete structure (China Communications Press, Beijing 2003).

[4] S.C. Cheng: Theoretical analysis of load capacity of reinforced concrete columns strengthened with reinforced concrete cover (Hunan University, Changsha 2003).

[5] F.Y. Hong, B.C. Chen: Journal of Fuzhou University(Natural Science).Vol. 36(2008), p. 272

[6] X.X. Cha, S.T. Zhong: Journal of Harbin University of C. E. \&Architecture. Vol. 30(1997), p. 41 